\title{
Las edificaciones cortesanas del Sitio Real de Riofrío
}

\author{
Juan Francisco HERNANDO CORDERO \\ Doctor en Historia del Arte
}

\begin{abstract}
RESUMEN. El Sitio de Riofrío fue diseñado por el arquitecto Vigilio Rabaglio por deseo expreso de la Reina Viuda Isabel de Farnesio a partir de 1752. Su fallecimiento en 1766 impidió la culminación del mismo y ninguno de sus herederos retomó la continuación del proyecto. El presente artículo trata de localizar y explicar las características de estas arquitecturas cortesanas que conformaban la Plaza de Armas que precedían al palacio, con la intención de facilitar la comprensión y dignificación del proyecto original, así como a la recreación histórica del ambiente cultural y social con el que fue concebido.

Palabras clave: Palacio de Riofrío, Isabel de Farnesio, Vigilio Rabaglio.
\end{abstract}

ABSTRACT. The Royal Site of Riofrío was designed by the architect Vigilio Rabaglio by express desire of the Queen Widow Isabel de Farnesio from 1752. His death in 1766 prevented the culmination of the same one and none of his inheritors recaptured the continuation of the project. The present article tries to locate and explain the characteristics of these court architectures that were shaping the Plaza of Weapon that were preceding the palace, with the intention of facilitating the comprehension and dignifying of the original project, as well as the historical recreation of the cultural and social environment with the one that was conceived.

Key words: Palace of Riofrío, Isabel de Farnesio, Vigilio Rabaglio.

El proceso de remodelación y de construcción de nuevos complejos residenciales en la España del siglo XVIII resultó ser una de las primeras consecuencias derivadas del cambio dinástico y de los nuevos monarcas de la casa Borbón. La adaptación a las nuevas formas de pensar, de vestir, de divertirse $\mathrm{y}$, cómo no, de gobernar, generaron una serie de necesidades que tuvieron que ser realizadas en un proceso lento pero continuado, y que contribuyeron a moder- nizar tanto las instituciones, como la arquitectura que las albergaba.

La nueva corte impulsada por Felipe V y sus dos esposas, María Luisa Gabriela de Saboya e Isabel de Farnesio, presentaba una serie de características continuistas de las tendencias barrocas de las grandes monarquías europeas, lideradas por Francia, Italia y Austria, que contrastaban fuertemente con lo construido en España hasta el año 1700. 
Los nuevos gustos, el elevado número de acompañantes, funcionarios, artistas, así como la multiplicidad de trabajos y servicios ligados a la real familia, generaron nuevas situaciones que obligaron a realizar importantes remodelaciones en los palacios y residencias de la anterior dinastía de los Austria.

A partir del segundo tercio del siglo, se inició una política dirigida a la construcción de nuevos conjuntos palaciales que aglutinaran todas las funciones cortesanas y que permitieran la plena gobernabilidad del país.

Fruto de esta tendencia se iniciaron los Sitios de San Ildefonso a partir de 1721, el Palacio Nuevo de Madrid tras el incendio del Alcázar en 1734, y el de Riofrío por iniciativa de Isabel de Farnesio a partir de 1752, que junto con las remodelaciones anteriores del Buen Retiro, el Pardo, Aranjuez o el Escorial, contribuyeron a crear un sistema de residencias de acorde a las nuevas necesidades regias.

El empaque y majestuosidad de estos palacios, muestra el interés por representar la nueva imagen de una monarquía moderna, renovada y poderosa, plenamente barroca y europeísta. Son precisamente estos complejos arquitectónicos los que, en buena medida, evocan el ambiente social de las clases altas de la época proporcionándonos una rica información sobre esta etapa histórica marcada por el lujo, el esplendor, la imagen y, cómo no, de la apariencia política.

El desarrollo arquitectónicourbanístico de San Ildefonso, el Pardo, Aranjuez, o el Escorial, continuó desarrollándose de una forma intensa e importante con la llegada de las nuevas corrientes ilustradas, pero no sucedió lo mismo con el inacabado proyecto de Riofrío, que tras la muerte de su promotora, Isabel de Farnesio, inició un proceso de abandono que impidió la ejecución de su proyecto original.

La aproximación a este complejo cortesano, constituye el principal objetivo de este artículo, tratando de identificar la funcionalidad y las características de las edificaciones que conformaban la plaza de armas y así comprender mejor el proyecto que Vigilio Rabaglio diseñó para la Reina Viuda y para el Infante Arzobispo-Cardenal D. Luis.

\section{EL PROYECTO PALACIAL DE RIO- FRÍO}

Tras la muerte de Felipe V en 1746, Isabel de Farnesio se retiró de la vida pública al Sitio de San Ildefonso acompañada por el único hijo al que no había podido conseguir un ducado que gobernar, el infante D. Luis. Aunque consiguió asegurar su nivel de vida con el Arzobispado de Sevilla y con el Cardenalato de Toledo, tuvo siempre una preocupación especial por su futuro. Con el objetivo de dotarle de una residencia digna a su rango y en un último arrebato de carácter y orgullo político, Isabel de Farnesio se lanzó a emprender la construcción de un sitio real de nueva planta que, en cierto modo, rivalizara con el Palacio Nuevo de Madrid diseñado por Sachetti y que ella misma mandó erigir junto a su difunto esposo.

Una vez elegido el término de Riofrío y tomada la decisión de construirse una nueva residencia, encargó a Vigilio Rabaglio la realización del proyecto palatino entre noviembre de 1751 y marzo de $1752^{1}$.

\footnotetext{
${ }^{1}$ Los diseños que Rabaglio realizó para Riofrío, se deben datar entre el segundo semestre de 1751 (tras la adquisición del término) y marzo de 1752, ya que los maestros interesados en presentar pliegos de condiciones ya podían ver la planta y alzado del complejo palacial, tal y como se desprende del Edicto enviado a los corregidores de Segovia, Salamanca, Valladolid, San Ildefonso y Madrid, el 16 de marzo de 1752, locali-
} 
Vigilio Rabaglio, protegido del Marqués de Scotti (ayo del Infante D. Luis y hombre de confianza de la Reina Viuda), realizó, los diseños de un complejo residencial presidido por un potente palacio de planta cuadrada de marcada inspiración italiana, precedido por una plaza de armas a la cual se abrirían las edificaciones cortesanas más representativas creando un ambiente escenográfico y urbanita, plenamente barroco ${ }^{2}$. (Fig. 1).

Y como no podía faltar en un proyecto de tal envergadura, diseñó también un conjunto de parterres y jardines que sirvieran para enlazar la arquitectura palacial con el entorno natural en el que se ubicaban.

Alineaciones de árboles, conformaban paseos y avenidas dentro de un potager salpicado de un programa escultórico a base de sencillas fuentes con temática mitológica, que generaban un entramado geométrico y de juegos de perspectivas que se complementaba a la perfección con el palacio.

La connivencia de majestuosidad, funcionalidad y plena integración de todas sus partes, son características que definen la

zado en el ARChivo General del Palacio Real de MADRID (A.G.P.), Sec. Administrativa, C ${ }^{\mathrm{a}}$ 1279/2:

"Se hace saber a todos los maestros Arquitectos, así de cantería, albañilería, y carpintería, que estándose para construir un Palacio de Campo de orden de la Reina Nuestra Señora, mi Ama en la Dehesa y Real Término de Riofrío, propia de S.M. que Dios guarde, los maestros de esta facultad que quieran dar pliego para executar dicha obra o parte de ella, acudan a el Real Sitio de San Ildefonso a tratar de esto con el Señor Secretario D. Juan Cascos Villademoros, Secretario del Real Despacho de S.M. que se les hará ver la planta y alzado, para que arreglándose a ella puedan con todo conocimiento dar sus pliegos, obligándose a executar la mencionada obra a destajo, siendo de cuenta de los maestros que la hicieren, todo género de materiales y herramientas para trabajar en ella".

${ }^{2}$ Arquitecturas y Ornamentos Barrocos: Los Rabaglio y el arte cortesano del siglo XVIII en Madrid, Madrid, 1997, p. 143. Proyecto general del Sitio de Riofrío, RBG/P-30. italianizante propuesta realizada por Vigilio Rabaglio para el futuro Sitio de Riofrío.

El hecho de que este vasto proyecto se financiara única y exclusivamente del bolsillo privado de la Reina Viuda, limitó en gran medida la incorporación de más edificaciones e infraestructuras. Por tanto, los planteamientos de Rabaglio se acomodaron al espacio disponible, a las necesidades de ocupación y gusto de Isabel de Farnesio, así como a los recursos económicos con los que se disponía.

El resultado fue un conjunto definido desde el primer momento como una unidad espacial que se mantuvo a lo largo de todo el proceso constructivo, a pesar de ser varios los Directores de las obras que sucedieron a Vigilio Rabaglio en la ejecución de este proyecto $^{3}$, debilitado de una forma importante tras el fallecimiento de Fernando VI en $1759^{4}$ y truncado definitivamente con el de Isabel de Farnesio en 1766.

\footnotetext{
${ }^{3}$ Vigilio Rabaglio fue el encargado de diseñar todo el conjunto arquitectónico, de dirigir la cimentación del palacio, así como de delimitar los espacios destinados a jardines y a la plaza principal. Estuvo en la dirección de las obras desde 1751 hasta febrero de 1753, momento en el que no aceptaría unas condiciones económicas y laborales que consideraba injustas y no acordes a sus pretensiones. Le sucedió en la dirección de las obras, su ayudante Carlos Frasquina (1753-1757), Pedro Sermini (1757-1762) y José Díaz Gamones (1762-1767), siendo este último el encargado de dirigir los trabajos de construcción de los edificios que complementaban al palacio hasta su paralización definitiva en 1767.

${ }^{4}$ El fallecimiento de Fernando VI supuso la entronización de la rama Borbón-Farnesio en la monarquía española en la figura de Carlos III y el final del destierro de Isabel de Farnesio en tierras segovianas. Riofrío perdía el sentido con el que se inició ya que sus destinatarios volvían a la corte y villa de Madrid, no siendo necesaria la construcción de una nueva residencia. El proyecto de Riofrío se continuó pero de una forma lenta y sin un futuro claro.
} 


\section{EDIFICACIONES DE LA PLAZA DE ARMAS}

Vigilio Rabaglio configuró un proyecto donde la simetría, las líneas de perspectiva y fuga, así como un ponderado reparto de espacios y volúmenes constituían sus rasgos principales. Como contrarresto a los grandes jardines ubicados al norte, en la fachada sur Rabaglio planteó un conjunto de edificaciones que vendrían a complementar las necesidades cortesanas y gustos de su promotora.

Organizadas en dos alineaciones enfrentadas a oriente y a poniente, estas edificaciones conformaban una espaciosa plaza de armas porticada de planta cuadrada con bordes redondeados, únicamente alterada por dos entrantes cóncavos que aportaban una sinuosidad y un carácter ondulante propio del barroco clásico italiano (Fig.2).

El carácter escenográfico de este conjunto vendría finalmente determinado por el telón de fondo natural que proporcionaba la serranía conocida como la Mujer Muerta y por el potente eje de perspectiva que marcaría el camino en dirección al recién abierto Puerto del León, en la sierra de Guadarrama, que comunicaría, de una manera ágil y rápida, este sitio con el Escorial y con el resto de residencias madrileñas.

Tal y como se define en los proyectos de Vigilio Rabaglio que se conocen, estas construcciones se conciben de una forma absolutamente subordinadas al palacio, no destacando en altura y tratando de ocultar su individualidad a través de fachadas sencillas unificadas por el pórtico que las precede y que aunaba estilísticamente a todo el conjunto.

La distribución espacial de estas estructuras atendía principalmente a criterios funcionales, identificándose claramente cinco grupos:
- Arquitecturas de servicio y abastecimiento del palacio: Casas de Oficios.

- Arquitectura lúdica: El Coliseo

- Arquitectura religiosa: Iglesia y Convento de Franciscanos

- Arquitecturas militares: Cuarteles de Guardias de Corps, Infantería Valona y Española, caballerizas y cocheras.

- Arquitecturas de habitación: Hostería y Casa para alojar a personas de distinción (Fig.3).

Vigilio Rabaglio enumeró cada una de estas edificaciones ubicando su localización en un documento explicativo que redactó para Isabel de Farnesio en los primeros meses de 1752 y que acompañaría a los diseños generales del Sitio. En este Plan general del Sitio de Riofrío, el arquitecto describía este conjunto de la siguiente forma:

"(...) Plaza que en su circunferencia contiene la Fábrica de Casa de Oficios, coronada de un pórtico, con tránsito superior todo unido al mismo Palacio para su pronto servicio.

Calle que sale de la misma Plaza que a un lado figura el Quartel de Guardias de Corps y al otro lado uniforme la Caballeriza para las Mulas y Caballos del Servicio de S.M., siguiendo ambos lados, Quartel de Guardias de Infantería.

Patio Rústico, con la Fábrica de Cocina de Boca y demás correspondencias.

Patio Cómodo a las luces y habitación de oficios.

Teatro cómodo para diversión del señor Infante u Familia.

Otro Patio Cómodo en dicha Casa de Oficios, que en su habitación, bajo y principal se podrán colocar médicos, botica y sus dependientes.

Huerta o herbolario a servicio y uso de la misma Botica.

Patio Rústico a la Casa de Oficios.

Quartel de Guardias de Corps con el cómodo de sesenta y ocho caballos, Habitación 
en el Bajo y Principal y cocheras para el Real Servicio. Españolas.

Quartel de Guardias de Infantería

Hostería o Posada para los Forasteros o pretendientes para la corte.

Sigue la Fábrica a la mano derecha que concluye a la Plaza.

Casa para aloxar a algunas personas de distinción, los que concurren o empleados al Real Servicio.

Quartel de Guardias de Infantería Balonas.

Caballeriza capaz y cómoda para ciento y cincuenta entre mulas y caballos, como también se hallarán cuatro cocheras para los coches de la Real persona, pajar y vivienda para los dependientes.

Patio Rústico para la Casa de Oficios.

Patio y Conventico, con la habitación de pocos religiosos arreglado a la Venerable Orden de San Francisco, junto con su huerta.

Iglesia capaz y unida al mismo Conventico, su corona y Tribuna, Cómodo a la Real Familia.

Patio cómodo a las luces de Casa de Oficios.

Otro patio rústico con fábrica de Cocinas de estado y habitación de los dependientes $(\ldots)^{\prime \prime 5}$.

Del análisis de este texto, de los diseños que se conservan en la Real Academia de Bellas Artes de San Fernando en la denominada Colección Rabaglio ${ }^{6}$, en las des-

\footnotetext{
${ }^{5}$ A.G.P., San Ildefonso C ${ }^{a}$ 1/14, Relación del plan general de la obra y Real Fábrica ideada por el arquitecto Vigilio Rabaglio de construirse en las cercanías del Real Bosque de Riofrío. Sin firma y sin fecha.

${ }^{6}$ En el año 1995, el Estado Español adquirió, procedente del mercado de arte suizo, dos carpetas que albergaban cuatrocientas obras, entre planos y dibujos, realizadas por los hermanos Pietro y Vigilio Rabaglio, conformando la que hoy se conoce como - Colección Rabaglio - . Fruto de esa adquisición, la Real Academia de Bellas Artes de San Fernando, organizó una exposición mostrando esta colección recién adquirida, fruto de la cual se editó un catálogo de todas estas piezas, constituyendo el único corpus que muestra la obra de los Rabaglio en España. El catálogo se titula Arquitecturas y Ornamentos Barrocos: Los Rabaglio y el arte cortesano del siglo XVIII en Madrid, Madrid,
}

cripciones del estado y evolución de las obras a la muerte de Isabel de Farnesio realizadas por el arquitecto Pablo Ramírez de Arellano, así como del estado actual de estas edificaciones, se puede plantear su intento de reconstrucción histórica y artística.

\section{LAS CASAS DE OFICIOS}

A diferencia de lo que ocurre en otros sitios reales, como en San Ildefonso, Aranjuez o el Pardo, en los que la Casa de Oficios constituye una edificación autónoma e independiente, en Riofrío adquiere una connotación diferente. La dispersión y la inclusión en dependencias palaciales de buena parte de estas funciones, favorecía una mayor atención, inmediatez y servicio a las personas reales que lo morarían. El hecho de que en la planta baja y tercera del palacio, así como en sus medianiles, ya se incorporaran buena parte de estos oficios dio lugar a que no fuera necesaria la creación de una edificación anexa de gran tamaño ${ }^{7}$.

Esta situación generó una descentralización pudiéndose distinguir cuatro casas de oficios. Anejas al palacio se localizarían dos fábricas de similar planta y distribución que se extenderían hasta la mitad de la plaza, delimitadas por el entrante cóncavo que precedería la fachada tanto del coliseo, como de la iglesia conventual de los franciscanos descalzos.

La de poniente albergaría los oficios de Boca, que incluirían todos aquellos que hicieran referencia a los menesteres culina-

1997. Planos № RBG/ P29 - P42. En esta colección tan sólo catorce dibujos hacen referencia al Sitio de Riofrío y concretamente tres, aportan información sobre la configuración de la Plaza de Armas, los RBG/ P-30 - P31 y P-32.

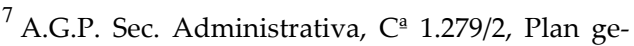
neral de aposentamientos del Palacio de Riofrío propuesto por Vigilio Rabaglio. 
rios y de abastecimiento destinados a cubrir la alimentación de Isabel de Farnesio y del Infante D. Luis, en primer término, y para todos sus servidores directos, siguiendo un estricto orden jerárquico (Mayordomo Mayor, Secretario, Contralor, Sumiller de Corps, etcétera), donde los platos sobrantes eran sucesivamente repartidos por los criados de inferior rango ${ }^{8}$.

La casa del lado oriental acogería a los oficios de Estado y en ella se proporcionaría la alimentación al resto del personal que no comía en Palacio, pero que tenían asignada ración de comida diaria, según su cargo. Militares, clérigos y caballeros que conformaban el séquito de la Reina Viuda y de su hijo, eran los destinatarios de los platos elaborados en estas dependencias.

Según sus plantas, insertas en el proyecto general que Rabaglio realizó de todo el Sitio, se vuelve a remarcar su obsesión por la simetría y por una distribución espacial en torno a dos patios, uno porticado que denomina - cómodo - y otro abierto de mayor tamaño llamado - rústico - (Fig. 4).

Los patios rústicos eran de mayores dimensiones, tenían una planta cuadrada, de veinticuatro metros de lado aproximadamente, y una única puerta de acceso por su lado sur. Se trataba de espacios abiertos a los que se abrirían un conjunto de dependencias donde se ubicaban cocinas, despensas y otras estancias relacionadas con el

-

${ }^{8}$ M. Á. PÉREZ SAMPER, «La alimentación en la corte española del siglo XVIII», Cuadernos de Historia Moderna, 2003, Anejo II, pp. 153-197.

En este trabajo se describen con minuciosidad las características tanto de los oficios como de los trabajadores y destinatarios, así como los alimentos que se dispensaban según los gustos de los monarcas borbones de esta centuria. Su clasificación encaja perfectamente con las citas documentales que hacen alusión a la distribución del personal de las casas de Isabel de Farnesio y del Infante D. Luis que aparecen mencionadas en el Plan general de aposentamientos que realizara Vigilio Rabaglio en 1752. abasto y suministro de piezas de volatería, potajería, sausería, panetería, cava, etc., perfectamente iluminadas y aireadas.

Los patios cómodos también mostraban una planta cuadrada de dimensiones más reducidas, de unos dieciséis metros aproximados de lado, con un pórtico, de unos dos metros de ancho articulado a través de arquerías de medio punto soportadas por cinco pilares, que tenía una función claramente diferenciada respecto al anterior. En este caso, estos patios servían de distribuidores de estancias de reducidas dimensiones que servían de alojamiento para los trabajadores y criados (Fig.5).

Las plantas altas tendrían también esta función de alojamiento y compartimentadas en apartamentos de diferentes superficies, comunicadas con el palacio a través de la galería que rodea toda la plaza sobre el pórtico. (Fig. 6).

Este enlace se producía directamente con la primera entreplanta, dónde continuarían piezas de alojamiento y de cocina de boca ${ }^{9}$.

En cuanto a su alzado, tan sólo contamos con dos referencias parciales sacadas de las secciones de la plaza y con la descripción de Rabaglio:

“(...) la Casa de Oficios, coronada de un pórtico, con tránsito superior todo unido

\footnotetext{
${ }^{9}$ A.G.P. Sec. Administrativa, C ${ }^{\mathrm{a}}$ 1.279/2, Plan de Aposentamientos del palacio de Riofrío, óp. cit,: “(...) Veinteidos Medianiles que corresponden al Quarto de la Reyna Nuestra Señora los que van distribuidos de este modo: Oficial de Contralor (1 pieza), Oficial de la Secretaría de la Reyna (1 pieza), Porteros de la Secretaría (1 pieza), panetería (1 pieza), cava (1 pieza), sausería (1 pieza), frutería (1 pieza), cerería (1 pieza), Estado de Caballeros (2 piezas), bruxería y potajería (1 pieza), furriera (3 piezas), guardajoyas, cozina de boca (5 piezas), el jefe de ramillete (1 pieza)".
} 
al mismo palacio para su pronto servicio $(\ldots)^{\prime \prime 10}$

Al exterior abierto a la plaza, no aparecería ningún elemento distintivo que aludiera a la funcionalidad de estas construcciones, ni siquiera mostraban una entrada principal que las diferenciara, quedando las tres puertas por las que se accedía, mimetizadas con el resto de las edificaciones a través del pórtico corrido, sobre el cual se alzaba la galería que las comunicaba con los medianiles del palacio.

El mismo esquema se repite en las otras dos casas de oficios localizadas en los extremos de la plaza a partir del Coliseo y de la iglesia del Convento.

En el ala occidental estas dependencias fueron destinadas como farmacia $\mathrm{y}$ como alojamiento del cuerpo médico; mientras que en su opuesto en el ala oriental fueron habilitadas como dependencias conventuales (las distribuidas en torno al patio cómodo que se utilizaría a modo de claustro), y las que cierran la plaza continuarían con la función de oficios de estado dirigidos principalmente a los oficiales y tropa de los acuartelamientos.

\section{ARQUITECTURA LÚDICA Y RELI- GIOSA. EL COLISEO Y EL CON- VENTO DE FRANCISCANOS}

El Coliseo y la Iglesia del Convento de Franciscanos, centraban la plaza de armas y su disposición enfrentada reflejaba los ideales propios de la época, entre lo lúdico y lo religioso y entre los placeres de la mente y del alma.

Sin lugar a dudas, constituían las arquitecturas de representación más impor-

${ }^{10}$ A.G.P., San Ildefonso C ${ }^{\mathrm{a}}$ 1/14, Relación del plan general de la obra y Real Fábrica ideada por el arquitecto Bigilio Rabaglio de construirse en las cercanías del Real Bosque de Riofrío. tantes, destacando sobre el resto de edificaciones en altura y con un sentido diferenciador claramente definido, a través de sus fachadas retranqueadas, generando un ritmo arquitectónico ondulante y dinámico propio de los ideales barrocos más clasicistas (Fig. 7).

A pesar de que estos inmuebles centrarían la vida cortesana fuera de los muros del palacio, seguirían teniendo una funcionalidad privativa de la Reina Viuda, de su Serenísimo Infante y de sus respectivos y reducidos cortejos. Esta nota refleja que aunque se trate de edificaciones que muestran unas dimensiones considerables, en ningún caso supondrían excelsas manifestaciones arquitectónicas.

El tamaño de ambos espacios se vio condicionado por el obsesivo carácter simétrico que Rabaglio pretendió dar a todo el conjunto, obteniendo como resultado un coliseo y una iglesia un tanto constreñidos y encajados de una manera forzada, sobre todo esta última.

En ambos casos, el arquitecto retoma soluciones que ya había puesto en práctica en otros proyectos previos, revelando quizás inseguridad ante planteamientos nuevos, o imposiciones estéticas por parte de Isabel de Farnesio, Scotti o el Infante D. Luis.

En el caso de la Iglesia del Convento Franciscano que se abriría en el centro del ala oriental, Rabaglio se está inspirando en la iglesia madrileña de los Santos Justo y Pastor, en la cual trabajaría entre 1742 y 1744 a las órdenes de Santiago Bonavía ${ }^{11}$. Esta iglesia formaba parte del complejo arquitectónico que el Marqués de Scotti

11 En la Colección Rabaglio, depositada en la Real Academia de Bellas Artes de San Fernando, aparecen ocho diseños relacionados con la iglesia de los Santos Justo y Pastor de Madrid, catalogados con las referencias RBG/P-1 - RBG/P-8. 
había mandado construir como palacio arzobispal para el infante - cardenal D. Luis, cuando éste tenía la edad de doce años $^{12}$.

En ambos casos, los templos presentan una planta basilical de nave única, sin capillas laterales y sin crucero destacado, en los que juega con bóvedas elípticas y arcos fajones. Sus cabeceras adoptan una fórmula semejante basadas en un ábside semicircular al interior, flanqueado por sacristías (Fig. 8).

Sin embargo la simetría que debía mantener todo el proyecto constituyó un serio problema para Rabaglio, a la hora de diseñar esta iglesia ya que tuvo que adaptar sus dimensiones a las del Coliseo, con el que hacía pendant y mantener una proporción respecto al resto de edificaciones de esta plaza de armas. Esta circunstancia obligó a acortar las dimensiones de la nave, respecto a su modelo madrileño, suprimiendo el módulo del crucero que precedía al presbiterio.

A pesar de esta circunstancia sus semejanzas son prácticamente totales. Rabaglio vuelve a repetir el mismo módulo de desarrollo vertical en su interior compuesto por un cuerpo bajo articulado por tres arcos de medio punto separados por pilastras de orden corintio sobre pedestal, que enmarcarían retablos que no fueron diseñados en este proyecto; y un cuerpo alto, asentado sobre una lineal cornisa, que antecede la apertura de una serie de óculos y ventana-

\footnotetext{
${ }^{12}$ R. GUERRA DE LA FUENTE, El Palacio Real y la arquitectura de Felipe V de Borbón. Siglo XVIII, Tomo I, Guía de Madrid y la Granja, Madrid, 1995, p.87. En 1739, al poco de iniciarse las obras del Palacio Real, el marqués de Scotti, ordenó el derribo de un viejo templo de la calle de San Justo y las edificaciones colindantes, adquiridas por el arzobispado de Toledo, obteniendo un solar de apreciables proporciones donde erigir la iglesia dedicada a los Santos Justo y Pastor y el palacio arzobispal para el cardenal-infante D. Luis.
}

les que proporcionarían una gran iluminación al templo. (Fig. 7)

Se desconoce la existencia de diseño alguno que mostrara el planteamiento de Rabaglio para la fachada de este templo, pero a ciencia cierta mantendría una estructura similar a la del coliseo, basada en una espadaña sobre el pórtico que unifica todo el conjunto.

En cuanto al Coliseo que se alzaría en frente, Rabaglio vuelve a retomar un modelo previo en el que había trabajado al poco de su llegada a España, en 1737, la remodelación del Coliseo de los Caños del Peral ${ }^{13}$. En la Colección Rabaglio aparece un diseño relacionado con este proyecto madrileño en el que se aprecian perfectamente sus semejanzas planimétricas ${ }^{14}$.

En ambos casos, Rabaglio se inspira en modelos juvarianos, adoptando la tradicional disposición barroca en forma de $\mathrm{U}$ inscrita sobre rectángulo, que continuaba con la arraigada ordenación de escena, proscenio, platea, vestíbulo y palcos, evidenciando la jerarquización del público asistente por categorías y grupos sociales ${ }^{15}$.

El único diseño de la fachada que se conoce se encuentra integrado en una sección longitudinal de las construcciones del ala occidental que forma parte también de la Colección Rabaglio ${ }^{16}$. El coliseo se destaca en el centro de la plaza con una sencilla espadaña decorada con frisos escultóricos en su banco y dos musas flanqueando a un

\footnotetext{
${ }^{13}$ F. DOMENECH RICO, La compañía de los Trufaldines y el primer teatro de los Caños del Peral, Tesis doctoral, UCM, Madrid, 2005, pp. 143-152.

${ }^{14}$ Arquitecturas y ornamentos barrocos, óp. cit., Planta realizada por Rabaglio atribuida al Coliseo de los Caños del Peral, RBG/ P- 56, p. 151.

15 J. F. HERNANDO CORDERO, «El Coliseo del Sitio Real de Riofrío», De Arte, № 8, 2009, pp. 87-102.

${ }^{16}$ Arquitecturas y ornamentos barrocos, óp. cit., Sección longitudinal de los edificios anexos al palacio, RBG/ P- 32, p. 143.
} 
Cronos sosteniendo un reloj. Dos potte de feus en torno a una esbelta cruz remataban todo el conjunto. Su acceso principal se destacaba a través de dos pilastras que soportan una placa con leyenda alusiva, sobre la que se alza el escudo de armas de los Farnesio. (Fig. 9).

\section{LA ARQUITECTURA MILITAR}

En cuanto a las arquitecturas de carácter militar es preciso distinguir la funcionalidad, los usos de este tipo de construcciones (cuarteles, cocheras y caballerizas) así como la diferenciación de armas. Continuando con las mismas líneas directrices de todo el conjunto, estos acuartelamientos no se destacarían apenas al exterior, quedando sometidos a la estética impuesta para todo el conjunto.

En Riofrío estaban representados los tres cuerpos fundados por el Rey Felipe V siguiendo los modelos de la Francia de su abuelo Luis XIV: la Guardia de Corps, la Infantería Valona y la Infantería Española.

Estos cuarteles ya respondían a los criterios establecidos a principios de siglo por teóricos en arquitectura militar, como Vauban, Belidor, o Muller ${ }^{17}$, en los cuales se definían perfectamente las características que debían tener este tipo de edificaciones, priorizando la comodidad de la tropa acuartelada, su control, su vigilancia, la defensa del puesto y el respeto a ciertas premisas urbanas $^{18}$.

Rabaglio organizó el ángulo suroccidental de la Plaza de Armas distribuyendo

${ }^{17}$ J. MULLER, Tratado de fortificación o arte de construir los edificios militares y civiles ( ...), traducido en castellano, y aumentado con notas, adiciones, 22 láminas por D. Miguel Taramas, Barcelona, Tomás Piferrer, 1769, t. I, pp. 192-193, 196 y 198.

18 A. RABANAL YUS, «El concepto de ciudad en los tratados de arquitectura militar y fortificación del siglo XVIII en España», Anales del Instituto de Investigaciones Estéticas, № 8I, 2002, pp. 33-52. un conjunto de edificaciones entre las que se destacaban el Cuartel de Guardias de Corps, el Cuartel de Guardias de Infantería Española, caballerizas, cocheras y una Hostería o Posada para los forasteros o pretendientes a la corte. (Fig. 10).

Su estructura, organizada en barracones rectangulares de dos alturas, serviría para alojar a la tropa y a las caballerías, resultando conjuntos abiertos y bien aireados, formando patios que a su vez repiten el esquema y el módulo cuadrado del palacio.

En las condiciones firmadas por los maestros asentistas en su escritura de obligación establecían, en su cláusula vigesimotercera, cómo y con qué materiales debían realizarse los conjuntos edilicios que cerrarían la Plaza de Armas:

“(...) Condición que en la formación de Caballeriza, Cocheras, quarto de Guardias de Corps, Guardias de Infantería Valones y españoles separado se deberá ejecutar bajo de la misma orden y disposición que va referida:

Que las columnas para la división de recuas de mulas y caballos deberán ser bien labradas como va expresada.

Que las puertas de entrada deberán ser formadas ambos lados de jambas despiezadas regulares.

Que se deberá solar de losa todas las entradas principales de tres cuartos de grueso todo asentando en cal a la mayor perfección

Que en los cuarteles se deberán formar en el medio a su crujía pilastras de cuatro paramentos, con su imposta despiezada regulares, las que se deberá construir sus arcos y bóveda de albañilería a toda la perfección debida (...)"19.

19 A.G.P., San Ildefonso, C ${ }^{\mathrm{a}}$ 13587, Copia authentica de la escriptura de obligación y condiciones para la construcción y obra del nuevo Real Palacio y fábrica del Real Sitio de Riofrío. Por real orden de la Reyna nuestra señora, la señora doña Isabel de Farnesio. Otorgada por Bartolomé Reale por sí y en virtud de 


\section{EL CUARTEL Y CABALLERIZAS DE LOS GUARDIAS DE CORPS}

Rabaglio definía estas edificaciones de la siguiente forma:

“(...) Quartel de Guardias de Corps con el cómodo de sesenta y ocho caballos, habitación en el bajo y principal y cocheras para el Real Servicio (...)" ${ }^{\prime 20}$.

Las Compañías Reales de Guardias de Corps fueron un cuerpo militar de élite creado en el año 1704 para velar por la custodia y protección personal del monarca. Formadas por los mejores soldados en valor, nobleza, confianza, robustez y presencia, llamaban la atención por la riqueza y vistosidad de sus uniformes. Al ser un cuerpo de caballería precisaba de espacios destinados para establos y caballerizas.

Ubicado en el ala occidental, es el único acuartelamiento del que se conoce su alzado y la representación exterior de su fachada y que, en cierto modo, hacía presuponer como serían las del resto de acuartelamientos del sitio (Fig. 11).

$\mathrm{Su}$ disposición mantiene el mismo lenguaje artístico - decorativo que el resto de edificaciones de la plaza, viniendo determinado por el pórtico y por la galería superior que servía como articuladora y distribuidora de las estancias interiores.

Todo el conjunto aparece rematado por ese coronamiento basado en fragmentos de balaustres y paramentos rematados por jarrones.

En el centro de la fachada se abría la portada que ordenaba el edificio en dos partes iguales y simétricas, caracterizada

poder de Andrés Rusca, maestros arquitectos, en $1^{\circ}$ de julio de 1752

${ }^{20}$ A.G.P., San Ildefonso C ${ }^{a}$ 1/14, Relación del plan general de la obra y Real Fábrica ideada por el arquitecto Vigilio Rabaglio de construirse en las cercanías del Real Bosque de Riofrío, apartado 10. por un arco de medio punto, flanqueado por dos pilastras adosadas que soportan una estructura adintelada, rematada por un frontón y por el escudo militar con las armas del cuerpo.

Su planta presentaba una disposición rectangular de cincuenta metros de largo por doce de ancho, dividida a su vez en tres naves longitudinales por dieciséis pilares de planta cuadrada, generando un entramado reticular destinado para cada uno de los departamentos donde se guardarían los sesenta y ocho caballos de este cuerpo, con sus correspondientes pesebreras, tal y como citó Rabaglio en su descripción general del plan.

Esta disposición longitudinal se ve alterada por un eje transversal que comunicaba la calle principal del Sitio con el patio articulador de las estancias de este acuartelamiento, dividiendo a las caballerizas en dos partes simétricas de ocho tramos y treinta y cuatro departamentos cada uno. El acceso a la planta superior se realizaría a través de dos escaleras situadas en los extremos.

En la parte posterior de este cuartel se situarían - las Cocheras - que presentaban una disposición espacial parecida. Una nave longitudinal organizada por dieciséis pilastras cuadradas generando un conjunto de departamentos donde guardar los coches de la familia real.

\section{LOS CUARTELES DE GUARDIAS DE INFANTERÍA ESPAÑOLA Y VALONA}

Los regimientos de Guardias Valo$\mathrm{na}^{21} \mathrm{y}$ Española, fueron creados al igual que el de Corps, siguiendo el modelo francés,

${ }^{21}$ Reciben este nombre de Balonas, Walonas o Valonas, debido a que este cuerpo de infantería fue reclutado originariamente en Flandes, fundamentalmente en la Valonia católica. 
como cuerpos de élite dentro del ejército, no para misiones de escolta, sino como unidades de combate, aunque también realizaban labores de seguridad ciudadana.

La intención de Rabaglio, quizás por sugerencia de Scotti o de la propia Isabel de Farnesio, era la de acompañar al complejo palatino de los tres cuerpos de seguridad, siendo sus funciones las del mantenimiento del orden público en el Sitio, así como velar por la protección de la familia real y del acceso a la plaza principal.

Ambos acuartelamientos volvían a ser simétricos y de reducido tamaño, basados en un pequeño pabellón de planta rectangular dividido en dos crujías por una alineación central de pilastras que organizaban el espacio interior. Tenían también dos alturas, accediendo al piso superior por unas escaleras situadas en uno de sus laterales. (Fig. 10).

Sus entradas principales se localizarían en su lado sur. A pesar de que no se conocen diseños que mostraran el acceso al complejo palatino desde su lado meridional, éstas seguramente seguirían el modelo utilizado en el Cuartel de Guardias de Corps.

\section{LAS CABALLERIZAS}

Se organizaron a través de dos pabellones paralelos, que repiten el mismo esquema que sus homónimas en el ala occidental y con las mismas dimensiones, cincuenta metros de largo por doce de ancho, pero organizadas interiormente con una mayor capacidad.

La caballeriza del lado occidental rematada por el pórtico que unifica toda la plaza presentaría un aspecto similar al del Cuartel de los Guardias de Corps y tenía una capacidad para sesenta y ocho compartimentos, treinta y cuatro a cada lado del zaguán y cuatro entre pilastra y pilastra.
La caballeriza interior presentaba una mayor capacidad al reducir el espacio útil de los departamentos, haciendo un total de ochenta y ocho, cuarenta y cuatro a cada uno de sus lados.

Ambos pabellones estarían unidos por una serie de dependencias, destinadas a servir de cocheras y estancias para los dependientes. $\mathrm{Al}$ igual que en el resto de estas edificaciones militares, el acceso a la segunda planta se produciría a través de escaleras localizadas en sus extremos.

El resultado de este conjunto, vendría a satisfacer el sentido simétrico que Rabaglio pretendía dar a todo el proyecto, obteniendo una fórmula muy parecida a la del ala occidental, basada de nuevo en el módulo cuadrado. (Fig. 10).

\section{ARQUITECTURAS DE ALOJA- MIENTO. LA HOSTERÍA Y CASA PARA ALOJAR A PERSONAS DE DISTINCIÓN}

Al no ser Riofrío un sitio destinado a albergar una abultada corte ni a recibir un gran número de invitados, - las arquitecturas de habitación o de residencia -, destinadas a esta función no eran ni grandes ni numerosas.

Tanto la Hostería como la Casa para alojar a personas de distinción, estaban pensadas como lugares para alojar a visitantes temporales de la familia real, repitiendo la misma planta y ubicación en la zona más alejada de la plaza. (Fig. 10).

No se conocen diseños ni citas historiográficas que aporten información sobre sus características y funciones, a excepción de sus plantas definidas en el proyecto general de Rabaglio y que coinciden exactamente con las cimentaciones que se conservan en el ala occidental de la plaza. Estas construcciones se limitarían a un conjunto de piezas con una clara función residencial. 


\section{DE DISEÑOS PROYECTADOS A EDIFICIOS REALIZADOS}

La ejecución de los diseños de Rabaglio para las edificaciones de la Plaza de Armas corrió a cargo de José Díaz Gamones, director de la que se puede considerar como cuarta etapa constructiva del Sitio de Riofrío, entre 1762 y $1767^{22}$.

El ritmo constructivo cayó de una forma considerable a partir de 1760, por lo que la evolución de estos trabajos fue lenta y trabada. Las tareas de desmonte y de nivelación de la plataforma sobre la que debían erigirse los edificios de esta plaza, contribuyeron a la ralentización de las obras y provocaron un desequilibrio en la evolución de las alas oriental y occidental. Cuando en 1766 se produjo el fallecimiento de Isabel de Farnesio, las diferentes arquitecturas construidas tan sólo llegaban a la mitad de la plaza.

El arquitecto Pablo Ramírez de Arellano fue el responsable de supervisar todos los trabajos de finalización de las obras, supervisar la dirección de Díaz Gamones, así como de inventariar todos los bienes muebles e inmuebles para incluirlos en la testamentaría de la difunta Reina ${ }^{23}$. Fruto

${ }^{22}$ J.F. HERnANDO CORDERO, El Sitio Real de Riofrío. Historia de un proyecto cortesano en la España del siglo XVIII, Tesis doctoral, ULE, 2008, pp. 238-246.

José Díaz Gamones, fue el director de las obras de Riofrío entre 1762 y 1767. Formó parte del proyecto desde sus inicios, comenzando a trabajar como medidor de Rabaglio y de Carlos Frasquina. Posteriormente se convirtió en ayudante de Pedro Sermini al que sucedería en la dirección de las obras tras su fallecimiento en 1762. Riofrío constituyó la escuela de formación de este arquitecto que desarrollaría sus mejores proyectos en la Granja Carolina, como la Real Fábrica de Cristales y el Palacio de los Infantes D. Antonio y D. Gabriel.

${ }^{23}$ A.G.P. San Ildefonso, C 13.618 , Informe realizado por PABLO RAMíREZ DE ARELLANO, arquitecto encargado por el Consejo de la Cámara de la Testamentaría de la Reina para conservar y preservar lo de estas acciones se conoce la situación exacta de las construcciones que se habían levantado hasta el momento.

Las edificaciones del lado oriental se hallaban en el siguiente estado:

“(...) La fábrica de la Casa de Oficios de la mano siniestra del Real Palacio y Convento, que por la Plaza Principal de Palacio está descubierta a poniente, constando su elevación y altura de bajo y principal en paredes de fachadas divisorias, con diversas escaleras, cubiertos todos sus pavimentos, bajo y alto de bóvedas, inclusa la que cubre su Galería que da principio desde el ángulo de la siniestra de la fachada principal de palacio con 14 arcos lineales y termina su continuación hasta la sección cóncava o placeta incorporada a la citada principal es la más adelantada de fábrica en lo que comprende a todas las Casas de Oficios contiguas por esta parte del Convento $(\ldots)^{\prime \prime}$

Las del lado occidental aparecían descritas del siguiente modo:

(...) Que las secciones de la fábrica de la Casa de Oficios, de mano derecha con vista a la Plaza de Palacio y Coliseo se hallan en altura de paredes divisorias y en fachadas exteriores e interiormente, descubierta la principal de este ramo de obra, a oriente en sólo altura del Quarto Bajo, continuando la misma todo lo comprensivo del lado derecho del Coliseo y centro del lado siniestro de él y en sólo 15 piezas de las muchas que se hallan en esta inmediación se ve estar hechos sus cubiertas y pavimentos de bóvedas (... $)^{24}$.

De estas descripciones de Ramírez de Arellano se desprende que en diciembre de 1766 se habían construido las Casas de Oficios inmediatas al palacio y se trabajaba sobre el alzado y las techumbres de la iglesia conventual y del coliseo

ejecutado en el Real Palacio de Riofrío, el 20 de diciembre de 1766.

${ }^{24}$ A.G.P. San Ildefonso, C ${ }^{\mathrm{a}} 13.618$, óp. cit., Informe realizado por Pablo Ramírez de Arellano, el 20 de diciembre de 1766 . 
Después de clausurar las obras de Riofrío en 1767, el Sitio se abandonó hasta que en 1784, Carlos III encargara al arquitecto Manuel Serrano la finalización de la Plaza de Armas ${ }^{25}$. Éste tan sólo pudo acometer la continuación de las dependencias del ala oriental, transformando y adaptando estos espacios a la nueva función que el monarca pretendía dar a estas construcciones, la de servir de caballerizas donde se alojara el séquito que le acompañara en sus jornadas venatorias en el término ${ }^{26}$.

Serrano partió desde la iglesia del convento, transformando su espacio de una manera muy significativa, dividiéndola en altura en dos plantas, sirviendo la inferior como cuadras y la superior para el alojamiento de la tropa.

A partir de aquí continuó levantando un conjunto de edificaciones que, si bien seguían el trazado original de Rabaglio al exterior, no hacían lo mismo al interior. La dificultad que ofrecía el terreno, ya que

\footnotetext{
${ }^{25}$ J.F. HERNANDO CORDERO, El Sitio Real de Rio-frío. Óp. Cit. pp. 246-248.

Manuel Serrano puede ser considerado como el arquitecto que dirigió la quinta y última etapa constructiva del Sitio de Riofrío entre 1784-1788. Formado en Aranjuez a las órdenes de Bonavía y de Marquet, realizó importantes ordenaciones urbanísticas en dicho sitio, así como arquitecturas como el Parador de San Ildefonso. Fue nombrado Académico de Mérito por la Real Academia de Bellas Artes de San Fernando en 1774 por su trayectoria urbanística e hidráulica en Aranjuez.

${ }^{26}$ A.G.P. Sec. Administrativa, C ${ }^{\mathrm{a}} 1.279 / 3$, Carta de Manuel Serrano al Conde de Floridablanca, en Riofrío a 15 de noviembre de 1784, en la que le comunicaba el estado en el que se encontraban las construcciones del ala oriental.

“(...) pasé a reconocer las Casas de Oficios del Palacio de Riofrío; formar el Plan y regular la obra que con la mayor economía se pueda hacer para usar las Cozinas y oficinas de Ramillete, Caba y otros oficios de boca; derribando las bóvedas que amenazasen ruina, y aprovechando lo que se pueda para hacer Caballerizas con separación, unas para las mulas y Caballos de la Casa Real, y otras para los Guardias de Corps, procurando regular el costo y las obras con la mayor economía (...)"
}

resultaba preciso ser barrenado para continuar con los dos pisos de estas edificaciones, dio lugar a que Serrano construyera directamente sobre la roca madre, limitándose a construir una sola planta, la superior, y ocultar la inferior con paramentos similares a los del resto de la plaza y prolongando el pórtico.

La distribución interior de estos nuevos espacios vino dada por su nueva función, construyendo pabellones rectangulares, patios y cocheras, así como espacios de habitación destinados a alojamiento del personal militar (Fig. 12).

El fallecimiento del arquitecto Manuel Serrano en 1787 y de Carlos III en 1788, determinan la paralización de las obras impidiendo la continuación de las construcciones del ala oriental.

El desinterés de los posteriores monarcas por Riofrío, provocó no sólo su no continuación, sino que consintieron un proceso de degradación que desembocó en la ruina total del Coliseo y de las Casas de Oficios de Boca del lado occidental a finales del s. XIX.

\section{CONCLUSIONES}

El desconocimiento de un mayor número de fuentes historiográficas, documentos, planos, secciones, alzados, etc., sobre el proyecto global de Vigilio Rabaglio y de sus sucesores en la dirección de las obras impiden, de momento, conocer más información sobre estas edificaciones cortesanas.

La reconstrucción e identificación de estas arquitecturas constituyen un primer paso para revalorizar y ensalzar a este sitio real inacabado, contribuyendo a la recreación del ambiente barroco, escenográfico y efectista pensado para este complejo palacial.

Su conocimiento y su rehabilitación deberían constituir puntos destacados en 
futuros procesos de restauración y de musealización, para así contribuir a la dignifi- cación de este desconocido y denostado conjunto artístico.

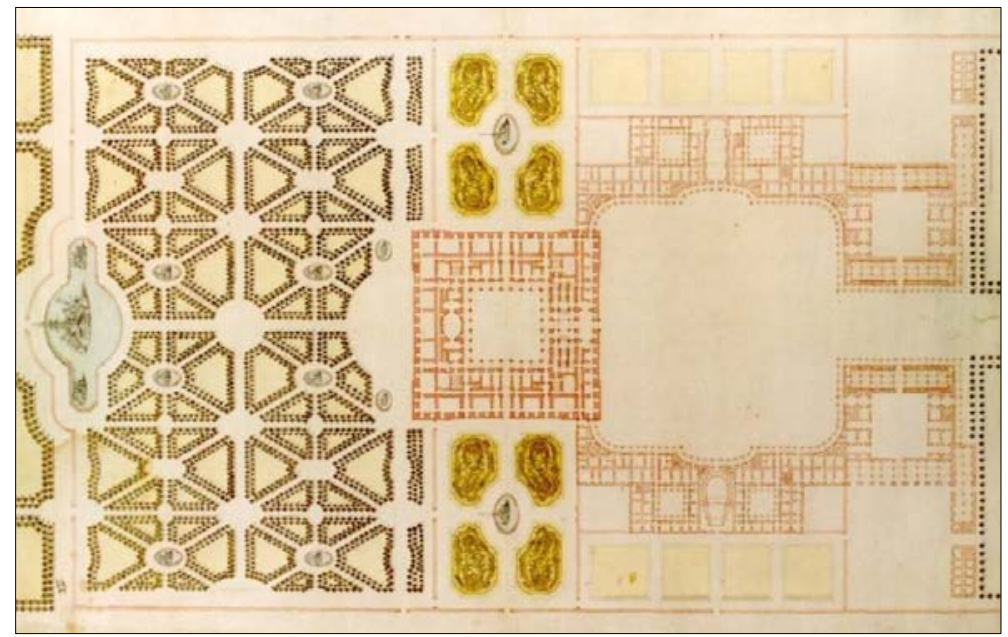

- Fig. 1. Proyecto general del sitio de Riofrío. Vigilio Rabaglio 175152. Colección Rabaglio. Real Academia de Bellas Artes de San Fernando (RABASF).

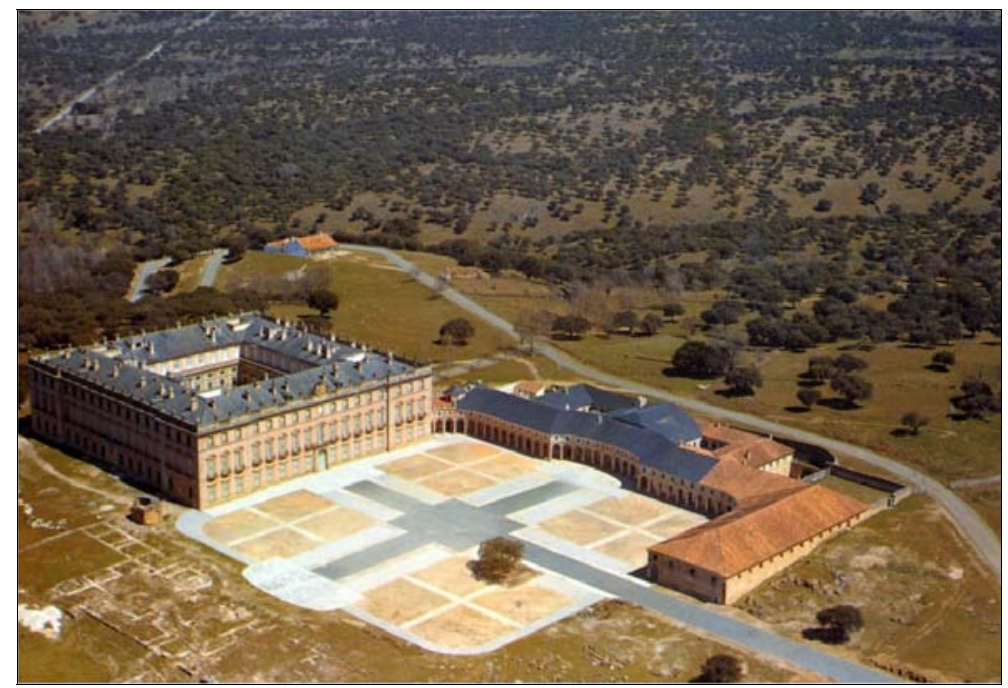

- Fig. 2. Complejo palacial de Riofrío. 


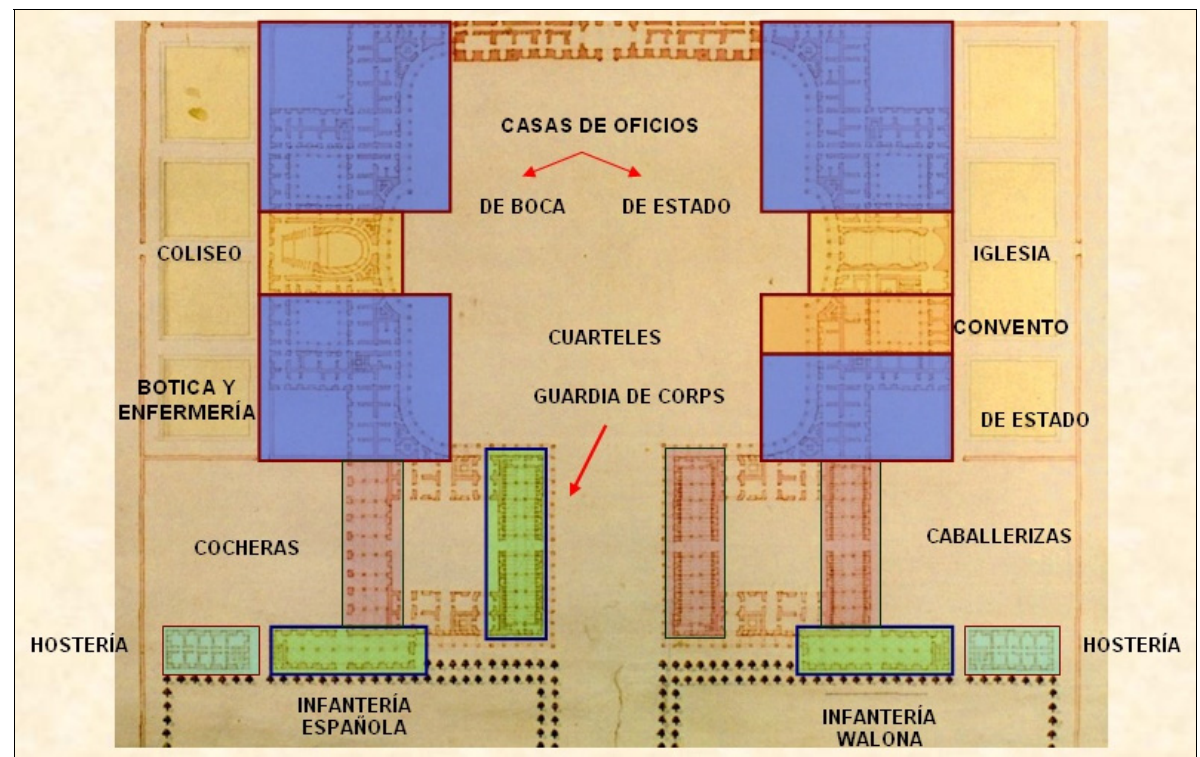

- Fig. 3. Identificación y localización de las edificaciones de la plaza de mediodía a partir del proyecto general del Sitio de Vigilio Rabaglio.

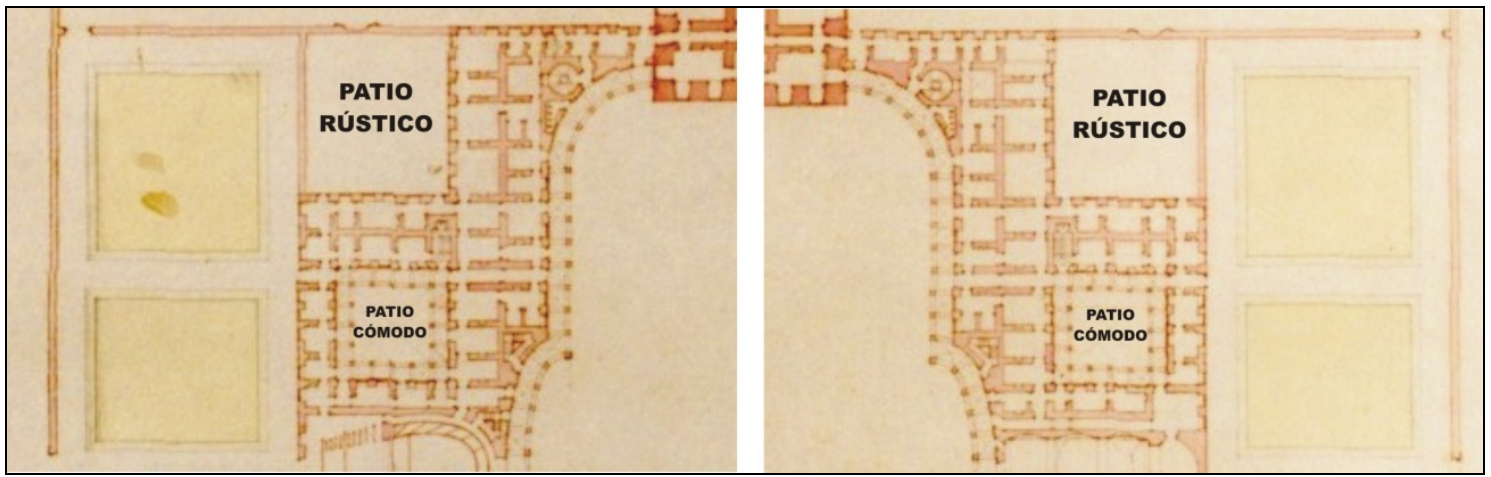

- Fig. 4. Plantas Casas de Oficios. Detalle del plan general del Sitio de Riofrío realizado por Vigilio Rabaglio. Colección Rabaglio RBG/P-30. RABASF. 


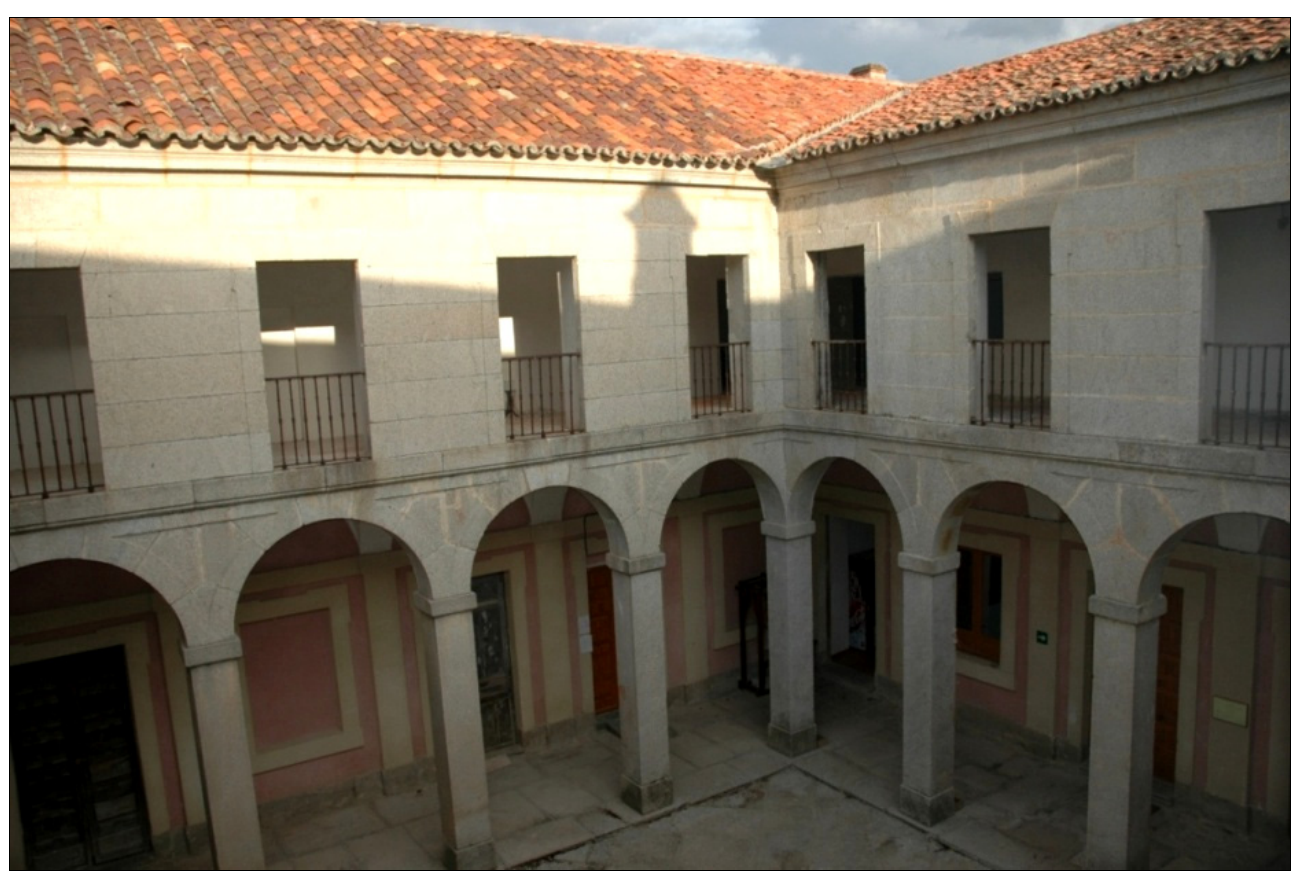

- Fig. 5. Patio cómodo de las Cocinas de Estado del lado oriental. Copyright (C Patrimonio Nacional.

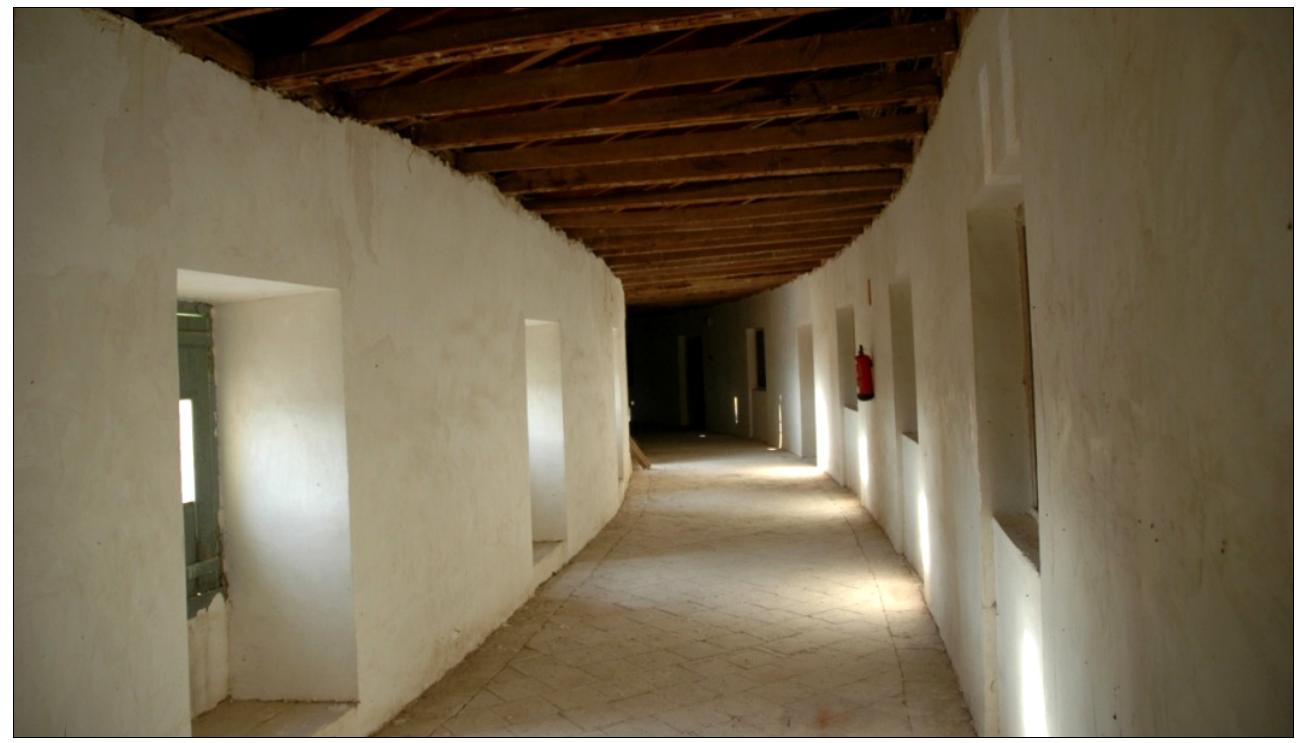

- Fig. 6. Corredor de la Casa de Oficios sobre el pórtico que comunicaba con Palacio. Copyright (C) Patrimonio Nacional. 


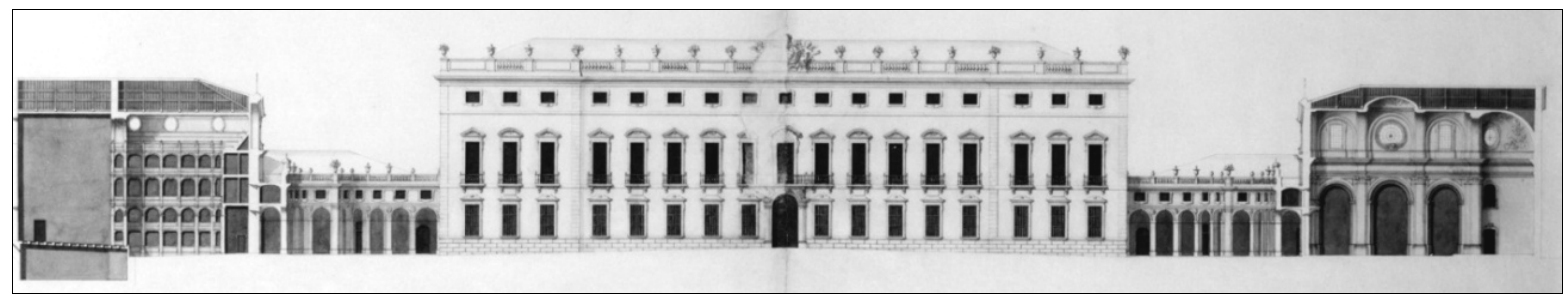

- Fig. 7. Sección transversal de la plaza de mediodía. Colección Rabaglio. RBG/P-31. RABASF.

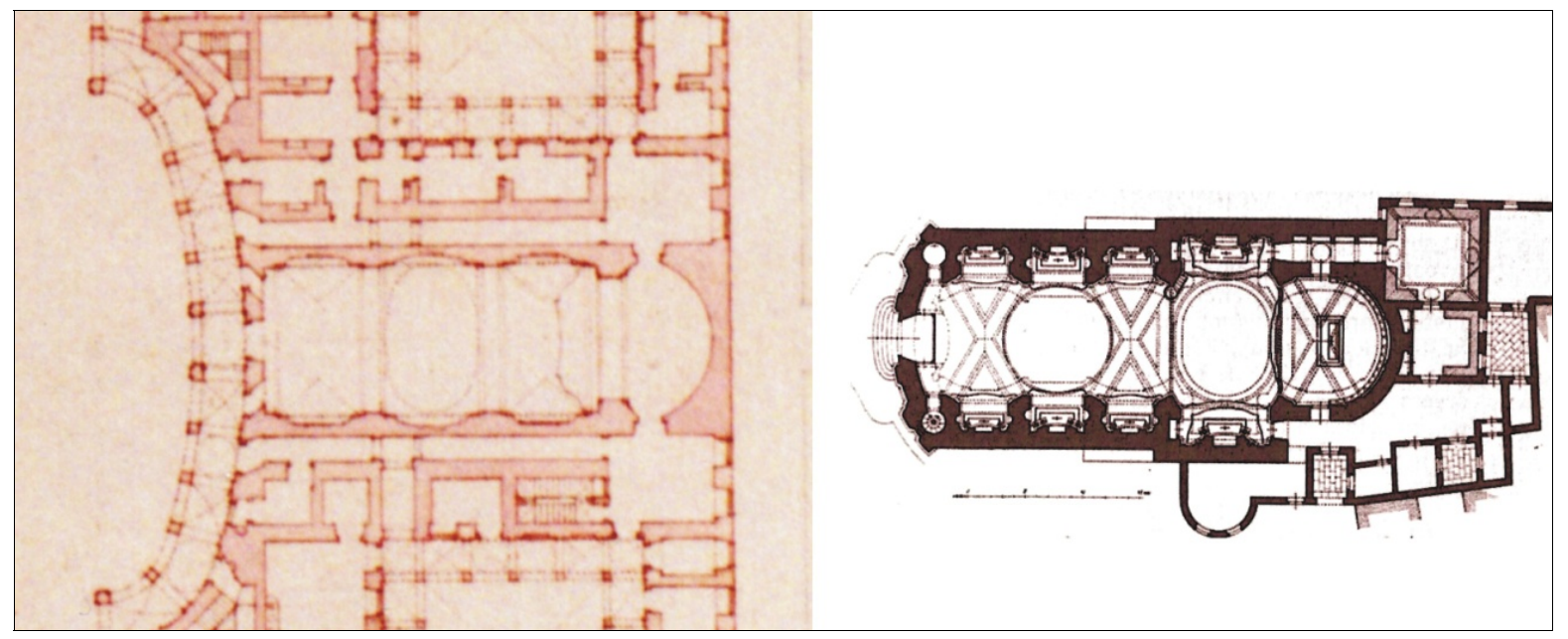

- Fig. 8. Detalle de las plantas de las iglesias de Riofrío y de los Santos Justo y Pastor. Colección Rabaglio. RBG/P-30. RABASF.

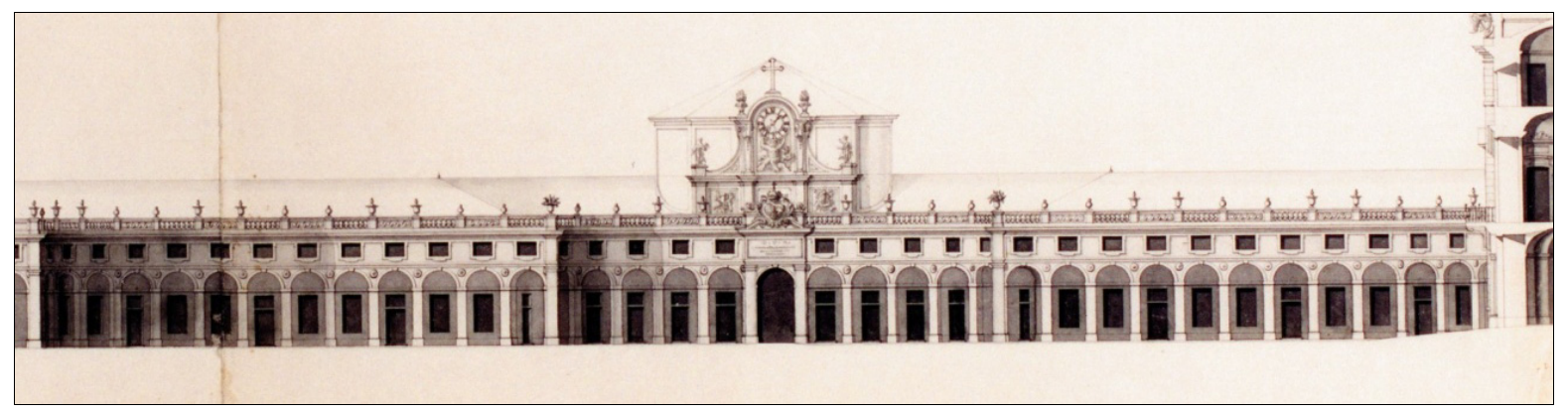

- Fig. 9. Sección longitudinal de de los edificios anexos al palacio, Colección Rabaglio, RBG/ P- 32, (RABASF). 


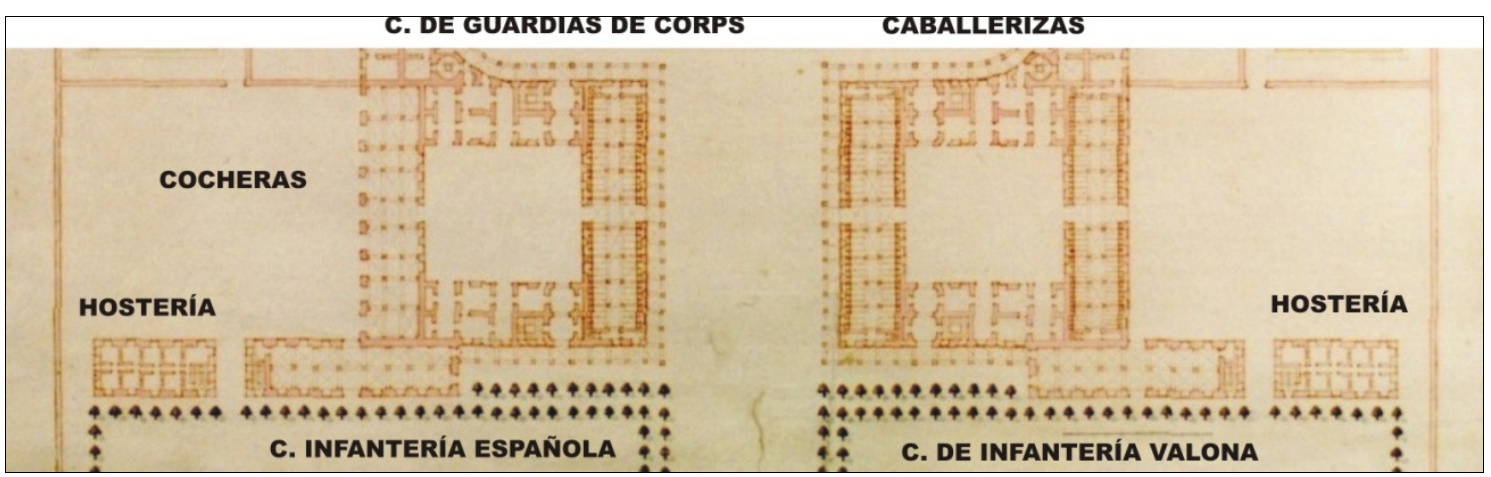

- Fig. 10. Localización de la Arquitectura Militar en el Plano general del Sitio de Riofrío. Colección Rabaglio. RBG/P-30, RABASF

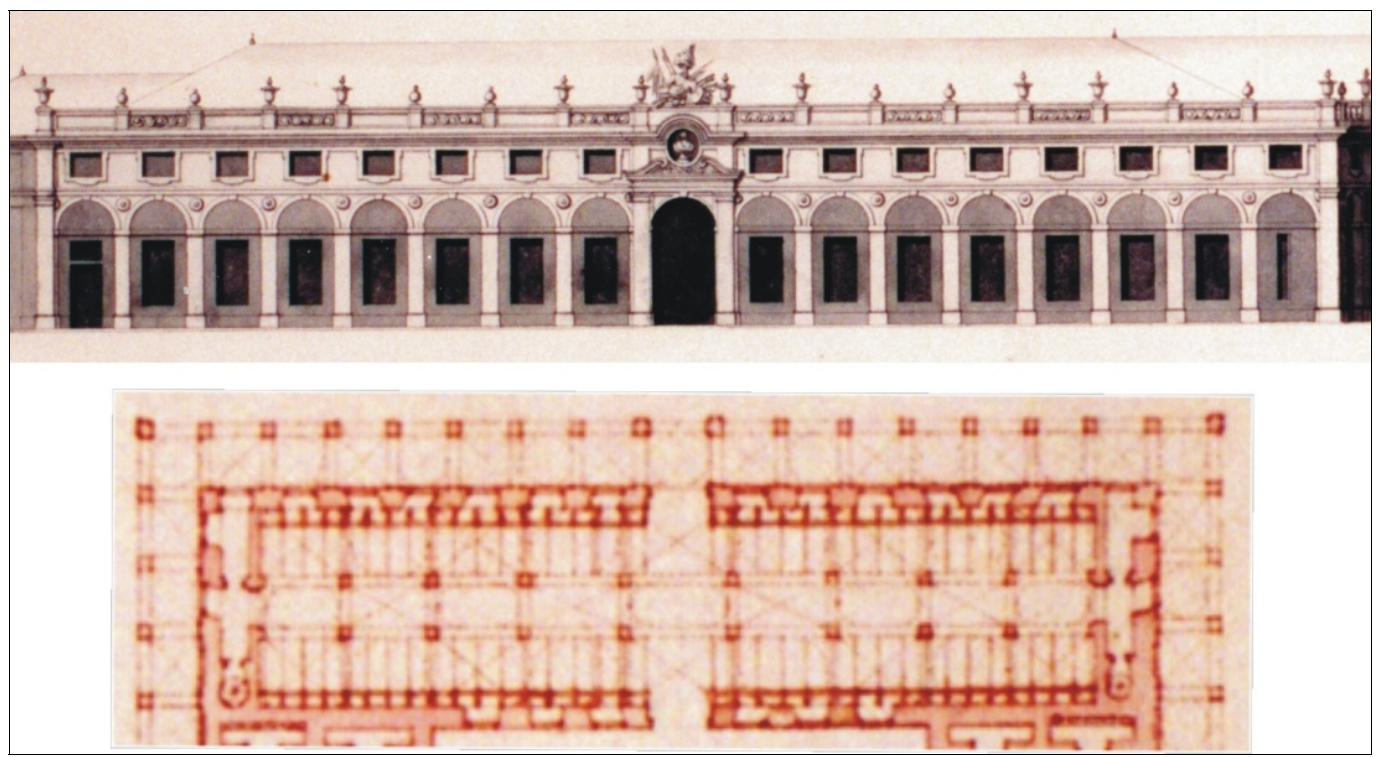

- Fig. 11. Planta y alzado del Cuartel de Guardias de Corps según detalles de los diseños de Rabaglio. Colección Rabaglio. RBG/P-30. RABASF. 